\title{
Creating Autonomy in the Advance of Teacher and Moral Educator Development
}

\author{
Paul A. Wagner ${ }^{1}$ \\ ${ }^{1}$ Research and Educational Psychology, College of Education, University of Houston, Clear Lake, USA \\ Correspondence: Paul A. Wagner, Research and Educational Psychology, College of Education, University of \\ Houston, Clear Lake, USA.
}

Received: November 18, 2021

Accepted: December 30, 2021

Online Published: January 6, 2022

doi:10.5539/jel.v11n2p22

URL: https://doi.org/10.5539/jel.v11n2p22

\begin{abstract}
The demand for character development in many of the Western World's public schools is increasing. Yet there are substantive steps being taken beyond manipulating student behavior in rigidly constructed contexts. Unfortunately manipulating behavior only develops self-interest as the measure of all good and might makes right the legitimation of authority. Yet as any anthropologist can explain it is role-modeling family and village elders that decides which of two instincts will dominate human development: self-interest or cooperation (Tomasello, 2019). As Aristotle famously observed, it makes no small difference what habits humans develop rather, it makes all the difference. But to be truly conducive to moral development those habits must reflect autonomous conviction to develop organizational well-being over the pandemonium self-interest leads towards. The Moral Self-assessment Protocol discussed herein creates the conditions for teacher and other leaders to track their own moral development to role model for those growing into organization membership, in schools, cities, states, countries and businesses.
\end{abstract}

Keywords: moral education, virtue, character, evolution, social inheritance, autonomy, noise in judgement

\section{Introduction}

Long ago psychologist Albert Bandura made the case for role-modeling as the most powerful of all social-learning practices (Bandura, 1976). Since that time Michael Tomasello and many other evolutionary psychologists have developed this line of thinking both to account for cultural differences around the world as well as for the species inclination to develop some balance between self-interest and cooperation and every social grouping large and small. Role modeling is so important some have even defined leadership as moral architecture (Wagner \& Simpson, 2009, pp. 2-3). Groupings dominated by self-interest lead to fracture and domination by defectors from group well-being. Defectors, those driven largely by self-interest, tend to turn every social engagement into a zero-sum game wherein someone loses to another's advantage. Things need not be that way. Humans have an instinct to cooperate. Cooperative organizations not only lead to greater comfort and security for all they minimize the tragedy of some dominating by tyranny over others. All begins with instinct. But all that matters is not mere instinct. A culture's role-models shape which of these two instincts dominates. One that favors the savagery of unbridled self-interest or one that encourages the flourishing of community success. Culture matters but it is not all that matters. Role modeling is as much a mammalian instinct as is self-interest and cooperation. If learning organizations such as schools are to develop robust sustainable societies, its leaders and other role models must be virtuous and worthy of role-modeling.

Below you will read about an instrument developed to help teachers originally then other societal leaders identify virtues each thinks worthy of development and then create a strategy for successful development of the virtues. Vices are developed similarly so it makes a great deal of difference which people chose to develop virtues or vices. In the current edition of the Moral Self-assessment Protocol (MSAP), there are instructions and a moral glossary with guidance for distinguishing between virtues and vices. With such distinctions in hand teachers and other leaders can identify virtues they want to develop in themselves and thereby enhancing the potency of their role-modeling such character traits to those the lead.

\section{Some Virtues are Obviously Good}

One of the challenges faced by every profession is to instill commitment of honor, integrity, and respect in their 
service to clients. At the same time, caution must be exercised not to usurp the credibility of diverse, cultural traditions of either the newly trained professionals or those they serve. To further these professional ambitions, organizations draw up codes of ethics to direct member attention toward professional ideals. Unfortunately, too often that attention is directed solely towards sanctions, avoidance of litigation and a growing literature of precedent outlining what is forbidden (Kahneman, Sibony, \& Sunstein, 2021). Rather than experience growth in their professions or in their personal moral development, today's professionals now are now too often haunted by a growing threat of censure, litigation, or impeachment. Yet, there is so much more that can be done to sustain a robust moral architecture for a profession's members and for those the members serve (Wagner \& Simpson, 2009; Wagner, 1983, pp. 87-88).

It is important to any developmental program that strategies for improvement be clear and can be systematically evaluated and tracked regularly. Psychologists have recently delved more seriously than ever before into the role of noise in human judgement. Noise is distinguished from bias by it lacking identifiable boundaries despite its sensitivity to statistical monitoring. For example, race and gender bias have been found to be identifiable for the bias towards others that they are. On the other hand, noise detects doctors prescribing antibiotics and sedatives more in the afternoon than morning and judges giving lesser sentences in criminal trials on pleasant sunny days that harsh cold days. The presence of the detectable noise is statistically evident, the precise driving force making these judgements vulnerable to noise is undetectable - only its presence is obvious. Noise contaminates moral judgment. Unfortunately, the only way to remove noise is to create behavioral rubrics disallowing for human judgment of any kind - ever. Yet that too is a problem since human judgment especially in the moral world needs tolerance for a bit of elasticity so mitigating circumstances can be considered effectively when appropriate. The focus of the MSAP on moral ideals and character development tempered by periodic and reasoned evaluation of morally guiding behavioral objectives brings together the most effective strategy of social-learning of morality to date.

Through the Moral Self-assessment Protocol (Wagner, Moral Self-assessment Protocol, 8th ed., 2004) teachers in training as well as leaders in advanced professional training of many sorts are given a strategic training tool for identifying and advancing their immediate and timely moral ambitions (Kierstead \& Wagner, 1993). As early as the 1990's the potency of the MSAP had been noted at a National Council for Accreditation of Teacher Education annual meeting when discussing the conclusion of the previous year's evaluations of teacher education accreditation programs. The outline of the Wagner instrument first appeared two years previously in a book on teacher education (Kierstead \& Wagner, 1993). The original publisher, Brown, was going to publish the instrument as an additional stand-alone item. They were bought out by Benchmark who asked for an instrument complete with a glossary and planning hints in addition to the directions and instrument itself. This was done. Several universities began using the instrument pilot versions of the instrument until the publisher could get all into print. Before Brown and Benchmark went to print with a marketable version in edition 3, McGraw Hill bought Brown and Benchmark and asserted their copyright rights on the MSAP. McGraw-Hill said if the product is already being used at colleges in four to seven different states at the time, they will continue printing it but, under their custom publishing division. At that point there were only a half dozen to a dozen universities using it, all waiting for when the product would become more generally marketed. McGraw Hill saw it as a teacher training instrument only.

\subsection{The Continuing Success of the Moral Self-assessment Protocol}

The MSAP is still used in teacher training programs but has also been used in business schools and professional organizations. All orders must go through McGraw Hill Custom. It owns the copyright and make it available only through direct sales.

In addition to the above, the MSAP has continued to be used in wider venues. It has been used in the American Leadership Forum training, Leadership Houston, in governmental ethics programs and the state of Texas included instruction during their annual ethics conference for senior governmental administrators at the LBJ School, University of Texas, Austin several years. Finally, when the author served on the Ethics Committee of the 40,000 member American Association of Public Administrators, I presented on the growing usage at that time in 1994. The need for general use of the instrument is increasing. Access to it remains a bit cumbersome but now that readers know to go through McGraw Hill Custom that should accelerate availability in its current 8th edition.

If wishes and good will were all it takes to develop morally, economically, fitness and intellectually everyone would be healthy, wealthy, and wise. But that's not the way it is. As Aristotle said long ago, "It makes no small difference what habits we develop, rather it makes all the difference." The MSAP is intended to direct wishes for 
improvement into realized habits deliberately acquired by autonomous persons (Wagner, 2004, pp. 16-17).

The MSAP instrument is accompanied by an extensive glossary of moral terminology. In addition, in includes a set of moral/logic facts as well as a section on "nearly factual morals" identified by recent psychological research. To prepare the user for implementing the instrument itself there are exercises for adult learners in addition to the directions and a section on helpful hints for scaffolding an individualized, strategic plan for either personal or professional moral development. The instrument tracks activities daily. Herein is the Aristotelian key for turning wishes for personal moral development into realities.

As key as the term moral is in the MSAP the term "Self" is equally central. The goal of being moral means all that one does regarding others must result from the user's exercise of personal autonomy. Being moral is not about a series of unrelated chance events. To truly be moral one possesses and pays attention to acquiring noble ambitions for others well-being and eschewing habits destructive towards others with whom one engages (Wagner, 1993).

Personal autonomy is intentional. It is self-building. It requires keeping an eye on virtues and not confusing virtues with chance events of fortune or misfortune nor with mere personality traits. Humans acquire personality traits through, evolution, genetics, and culture (Wagner \& Lopez, 2010). This means personality traits are things that humans have little if any control over. Whereas we are rightly credited with either praise or condemnation for the virtues we are believed to have built into self-aware experience (Pinker, 2021, pp. 180-181).

Humans have no control over the species' evolution. Humans do not control their own genetic nor family social inheritance. These shaping forces happen to people and are not self- originating. Culture matters but it is not all that matters (Rhaini, 2021; Tomasello, 2019; Sapolsky, 2017; Bowles \& Gintis, 2013).

As persons acquire experience, they potentially acquire as well substantial control over action selection in context (Bloom, 2005). Choosing actions and developing habits of choosing actions that serve the well-being of self and others is no mere happenstance or at least not necessarily so (Bloom, 2016; Gopnik, 2010). Self-selected actions and habits instance character traits and developing autonomy. As the American Psychological Association recently designated them, virtues, are deliberatively selected for by autonomous persons acting with intent to build virtuous, character (Peterson \& Seligman, 2003). A community of autonomous individuals setting out to build a community of reciprocal, shared commitment becomes robust and is likely to survive and thrive as well (Scheffler,1990).

Imagine such a morally inspired community fostered and protected by morally conscientious adults. Such a community could be described as having a responsible sense of patriotism at least in the sense of Martin Luther King Jr's, "I have a Dream speech". The speech testified not to shaping experiences of the past as much as what an inspired community could make happen in the best interests of everyone (King, 1963). The communities King dreams of stand in stark contrast to jingoistic tribalism. King's communities are deliberately chosen derived from what he calls "self-evident truths" crafted to bring all members to the table as "brothers and sisters" and without ire told suspected outsiders. This spirit of patriotism is far from a zero-sum game ethos so common to those predators today whose jingoism is a threat to all as happened during Robespierre French Revolution (Wagner, 1993).

Developing virtuous character and cooperating to build communal well-being is a deliberate undertaking that scaffolds a better person and respectful engagement with others (Gardner, 2011). This involves not only seeking the best for all involved but doing all one can to avoid injurious consequences for every other well-meaning participant in the collaboration (Scheffler, 1990). People of good character are not only accommodating neighbors and citizens but assets in the building of every organization of which they are apart (Dewey, 1916). People of good character refuse to see others as mere objects to be manipulated for one's own a cliques' self-centered ambitions (Wagner \& Siegel, 1988).

The MSAP is a practical hands-on instrument which aides student-building aspirations for democratic education. Surely something in alignment with King's dream. Moral communities are built on a foundation of autonomous and morally committed adults. The MSAP had previously been applauded by an NCATE Visiting team when visiting a university using it for this very reason: it continued in systematic fashion the development of teachers prepared for contributing to such community - building through their success in moral student-building (Wagner \& Fair, 2020). The MSAP is a singularly unique device that that creates a strategy for teachers to identify and then track their own personal and professional moral and patriotic development.

\section{A Further Note on the History and Rationale of the MSAP}

The focus of the instrument itself originally reflected the author's work with psychologist Lawrence Kohlberg to 
give learners direction through developing stages of morality. Since then, the MSAP has been re-shaped several times to make it more versatile and not regimented to prescriptive stages of right-minded behavioral thinking. Instead, the evolved MSAP accommodating new understanding of evolution and game theory addresses a set of elements for analyzing morally appropriate engagement with others (Wagner, Johnson, Fair, \& Fasko, 2018). These adaptations to accommodate reflective analysis in continuous fashion is in line with contemporary work in mathematical game theory as developed in biology and economics showing that expected utility can be calculated for the benefit of all achieving at least non-injurious equilibrium for all engaged in the evolving community and world structures (Raihani, 2021). By showing learners that in all human engagements, both values and likelihoods can be brought together to create a tolerable equilibrium for all, all learners can see the importance of rationally constructed tactics and strategies for becoming increasingly moral as a conscientiously aware self (Wagner, 1981). In short, as Kohlberg and so many others anticipated systematic moral development can happen and when it does communities are strengthened and flourish (Mlowdinow, 2015).

\section{Conclusion}

The MSAP underscores the centrality of preserving individual autonomy at the same time it produces robustly cooperative communities. Moral development cannot properly be downloaded onto people (Brighthouse, Ladd, Loeb, \& Swift, 2017; Bandura, 1976). Indoctrination makes social learning less than optimal (Kahneman, Sibony, \& Sunstein, 2021). The MSAP builds on evolved human nature and sparks reciprocal respect for others autonomy. The MSAP builds moral individuals and in a community wherein MSAP training becomes common place, the MSAP builds resilient moral communities.

\section{Best Practices for Using the MSAP Instrument}

1) Discuss the "Instructions" and "Helpful Hints" with students. Make sure they understand the difference between Goals (moral ideals) and objectives (measurable steps to do or avoid each day). Similarly make sure students know the difference between "Evaluation" and Assessment". There are available exercises that can be used to help students who are having difficulty discriminating between these distinctions.

2) Discuss the Glossary terms with students. In particular", be sure students know the difference between "character traits "and "personality traits" and "actions" as opposed to mere "behaviors." Distinguish "ideals" from "action plans".

3) Explain to students that the moral truths listed are just as easily understood as strictly truths of formal logic (For example, the law of contradiction).

4) Discuss with students research findings from evolutionary psychology and elsewhere testifying to the human instincts for cooperation and self-interest as nearly moral truths.

5) Have the students list at least two moral ideals each student chooses to work on.

6) Once they have ideals (as opposed to personality traits) identified have them list three to five objectives they will monitor daily for the next specified length of time as the set out to create or end habits that will bring each student closer to his or her own specified moral ideals listed in the MSAP protocol instrument.

7) When the specified time is complete the student reviews degree of success evaluating his or her performance creating or terminating a habit as prescribed in objectives given the information contained in the daily column of assessment data.

8) Lastly, students fill in a planning column leading to how they would change their protocol it they were to go through another round of assessment with the same ideals in mind as their goals.

\section{References}

Bandura, A. (1976). Social learning theory. Englewood Cliffs, NJ: Prentice-Hall.

Bloom, P. (2005). Descartes' baby: How the science of child development explains what makes us human. New York, NY: Basic Books.

Bloom, P. (2016). Against empathy: The case for rational compassion. New York, NY: Ecco.

Bowles, S., \& Gintis, H. (2013). A cooperative species: Human reciprocity and its evolution. Princeton, NJ: Princeton University Press.

Brighthouse, H., Ladd, H., Loeb, S., \& Swift, A. (2017). Educational goods: Values, evidence, and decision-making. Chicago, IL: University of Chicago Press. https://doi.org/10.7208/chicago/9780226514208.001.0001 
Dewey, J. (1916). Democracy and education. New York, NY: Macmillan.

Gardner, H., (2011). Truth, beauty, and goodness reframed: Education For the virtues in the age of truthiness and twitter. New York, NY: Basic Books.

Gopnik, A. (2010). The philosophical baby: What children can tell us about Truth, love, and the meaning of life. New York, NY: Farrar, Straus \& Giroux.

Kahneman, D., Sibony, O., \& Sunstein, C. R. (2021). Noise: A flaw in human Judgement. New York, NY: Harper

Kierstead, F., \& Wagner, P. (1993). The ethical, legal, and multicultural Foundations of teaching. New York, NY: McGraw-Hill.

Mlowdinow, L. (2015). The upright thinkers: The human journey from trees to understanding the cosmos. New York, NY: Pantheon.

Peterson, C., \& Seligman, M. (2003). Character strengths and virtues: A Handbook and classification. New York, NY: American Psychological Association.

Pinker, S. (2021). Rationality: What it is. why is seems scarce. why it matters. New York, NY: Viking Books.

Raihani, N. (2021). The social instinct: How cooperation shaped the world. New York, NY: St. Martin's Press.

Sapolsky, R. (2017). Behave: The biology of humans at our best and worst. New York, NY: Penguin.

Scheffler, I. (1990). On human potential. New York, NY: Routledge.

Tomasello, M. (2019). Becoming human. Cambridge, MA: Harvard University Press. https://doi.org/10.4159/9780674988651

Wagner, P. A. (1981). Moral education and the principle of minimizing substantive, moral error. Proceedings of the Thirty-seventh Annual Meeting of the Philosophy of Education Society, 37, 191-198.

Wagner, P. A. (1983). The idea of the moral person. Journal of Thought, 18(2), 83-96.

Wagner, P. A. (1993). Against cultural relativism. Journal of Educational History and Philosophy.

Wagner, P. A. (2004). The Moral Self-assessment Protocol (7th ed.). New York, NY: McGraw-Hill Custom Publishing.

Wagner, P. A. (2010). Formalizing thinking for morally responsive administration. Values in Ethics and Educational Administration, 8(2), 1-8.

Wagner, P. A., \& Fair, F. (2020). Education for knowing: Theories of knowledge for Effective student-building. New York, NY: Rowman \& Littlefield.

Wagner, P. A., Johnson, D., Fasko, D., \& Fair, D. (2018). Thinking ahead: Engaging all teachers in critical thinking. New York, NY: Rowman \& Littlefield.

Wagner, P. A., \& Lopez, G. (2010). The great conversation and the ethics of inclusion. Multicultural Perspectives, 12(3), 167-172. https://doi.org/10.1080/15210960.2010.504496

Wagner, P. A., \& Siegel, H. (1988). The moral responsibility of corporations. Journal of Thought, 11(3), 14-16.

Wagner, P. A., \& Simpson, D. (2009). Ethical decision-making in school Administration. San Francisco, CA.

\section{Copyrights}

Copyright for this article is retained by the author, with first publication rights granted to the journal.

This is an open-access article distributed under the terms and conditions of the Creative Commons Attribution license (http://creativecommons.org/licenses/by/4.0/). 